\title{
ANALISIS FAKTOR-FAKTOR YANG MEMPENGARUHI KEINGINAN WAJIB PAJAK DALAM MENGGUNAKAN E-FILING DI KOTA BATAM
}

\section{Muhammad Jufri}

${ }^{1}$ Sistem Informasi, Universitas Internasional Batam, Jl. Gajah Mada - Baloi email: jufri@uib.ac.id

\begin{abstract}
Acceptance receipts for the Director General's e-filing system ask for online services. Significant inquiries were made to identify indicators that support the system was accepted and accepted This Penelitian bertujuan buat mengetahui korelasi antara variable performance expectancy, effort expectancy, social influence, facilitating condition dengan behavioral intention para wajib pajak warga terhadap e-filing system DG pajak. The data collection was carried out using a questionnaire that totaled 250 which were distributed in Batam City to all the people. The samples used were selected randomly from the public who have used the system and have not used the efiling system. Due to the results of the testing in this study, it shows that the variable intent. erformae expectancy, expectancy effort and facilitating ondition are very hard Meanwhile, what will happen in the test on variable social influenza does not affect the desire to use the e-filing system.
\end{abstract}

Keywords: effort expectancy, facilitating condition, Performance expectancy, social influence, $e$ filing

\begin{abstract}
Abstrak
Penerimaan terhadap sistem e-filing Ditjen pajak terhadap layanan online laporan pajak penting dilakukan buat mengetahui indikator bahwa sistem diterima serta diterapkan oleh masyarakat untuk mendukung proses pelaporan pajak. Penelitian ini bertujuan buat mengetahui korelasi antara variable performance expectancy, effort expectancy, social influence, facilitating condition dengan behavioral intention para wajib pajak warga terhadap sistem e-filing Ditjen pajak. Pengumpulan data dilakukan menggunakan cara membuatkan angket yg berjumlah 250 yang disebar di kota batam pada seluruh rakyat. Sampel yang digunakan dipilih secara acak dari para masyarakat yang sudah memakai sistem dan belum memakai sistem e-filing. akibat pengujian pada penelitian ini memberikan bahwa variable performance expectancy, effort expectancy serta facilitating condition sangat berpengaruh terhadap behavioral intention sistem e-filing Ditjen pajak. Sedangkan yang akan terjadi pengujian di variable social influence tidak memberikan pengaruh terhadap hasrat penggunaan sistem e-filing.
\end{abstract}

Kata Kunci: effort expectancy, facilitating condition, Performance expectancy, social influence, $e$ filing

\section{PENDAHULUAN}

Perkembangan teknologi informasi sangat pesat dimasa kini salah satunya sistem informasi (Masril \& Noviardi, 2020). Pemanfaat teknologi dan gosip sangat dibutuhkan khususnya untuk kegiatan pelayanan akademik pada perguruan tinggi. Sistem infomasi akademik ialah sistem yg mengatur pengelolaan akademik dan mengatur segala aktivitas mahasiswa pada perguruan tinggi. buat melakukan evaluasi sistem informasi akademik bisa dilakukan 
menggunakan mengukur tingkat pemahaman serta kepuasan berasal sistem tadi. terdapat beberapa contoh buat mengevaluasi sistem isu akademik salah satunya ada metode Theory Of Acceptance and Use Of Technology (UTAUT). Beberapa penelitian menggunakan Theory Of Acceptance and Use Of Technology (UTAUT) buat mengukur tingkat penerimaan sistem isu antara lain:

Penggunaan teknologi pendidikan baru mirip Interactive Whiteboard (IWB) menjadi media mengajar bagi guru, perlu adanya penyesuain agar potensial pemanfaatan IWB lebih baik. Meskipun banyak upaya buat mengajak pengajar memakai teknologi pendidikan baru, namun terdapat perasaan apakah para pengajar akan mendapatkan atau tidak. pada penelitian ini diusulkan memakai metode Theory of Acceptance and Use of Technology (UTAUT) menggunakan memakai 2 variabel moderator yaitu pra serta pasca penggunaan IWB. hasil Pengujian 2 variable pra serta pasca penggunaan IWB disimpukan, bahwa niat pengguna teknologi IWB lebih bertenaga sesudah mencoba menggunakannya (Šumak \& Šorgo, 2016).

Faktor-faktor penerimaan teknologi transportasi baru yaitu bicycle sharing systems menggunakan mengidentifikasi serta mendeskripsikan hubungannya niat serta sikap pengguna memakai versi teranyar dari (UTAUT 2).

Penelitian ini mengPengujian imbas Perfomance Expectancy, kondisi fasilitas, pengaruh sosial, nilai harga, serta persepsi keamanaan terhadap penerimaan bicycle sharing systems pada Mashhad (MBBS) Iran. sebanyak 600 kuisioner didistribusikan pada 128 stasiun MBSS dimana 271 pengguna merespon. akibat membagikan niat buat menggunakan MBSS ialah syarat fasilitas yg digunakan. Temuan penelitian ini menyarankan perbaikan syarat fasilitas mirip integrasi angkutan awam MBSS, relokasi stasiun, memperkenalkan kampanye motivasi buat menaikkan stastus sosial bersepeda, dan mempertinggi layanan sebagai akibatnya membuat MBSS lebih menarik bagi warga (Jahanshahi, Tabibi, \& van Wee, 2020).

Penerimaan terhadap teknologi isu khususnya sistem infomasi di akademik keperawatan pembina palembang. penelitian ini bertujuan penerimaan sistem berita akademik memakai Unified Theory of Acceptance and Use of Technology (UTAUT) 2. Pengujian pada penelitian ini memakai variable primer dan variable moderasi. Data penelitian ini didapat menggunakan informasi lapangan memakai 135 responden terdiri dari 113 sample mahasiswa dan 22 sample asal dosen.

Akibat peneltian menunjukkan variable ekpektasi kerja $(16,46)$, espektasi usaha $(16,54)$, pengaruh sosial ()14.85, motivasi hedonis $(6,18)$, nilai harga(16,59), norma $(15,94)$ terhadap niat pelaku. Variabel syarat fasilitas (dua.22) terhadapa perilaku pengguna. UTAUT 2 bisa menghipnotis penerimaan sebesa 9,4\% (Anggraini, Irfani, \& Rahayu, 2020).

Pengujian penerimaan sistem isu akademik pada Universitas Islam Negeri Raden Fatah Palembang. Pengujian memakai dua variable yaitu validitas dan reliabilitas. Pengujian variable validitas dengan melihat nilai asal average variance extracted (AVE) serta nilai latent variable correlations sedangkan Pengujian reliabilitas menggunakan nilai composite reliability. Pengumpulan data pada penelitian ini denga cara menyebarkan informasi lapangan secara online pada mahasiswa UIN Raden Fatah Palembang. akibat Pengujian variable validitas serta reliabilitas seluruh indikator Pengujian data dinyatakn valid reliabel dengan nilai AVE $>0.50$ serta nilai composite reliability $>0.70$. Pengujian di variable validitas diperoleh variabel ease of use dengan nilai AVE tertingggi yaitu 0.826. sedangkan Pengujian di variable reliabilitas diperoleh variabel performance 
expectancy menggunakan nilai composite reliability tertingggi yaitu 0.924 (Aprilisa, Samsuryadi, \& Sukemi, 2021).

Aplikasi pembelajaran online sangat populer dan sudah menjadi kenyataan awam dalam sistem pendidikan terbaru memakai mobile learning. penelitian ini menerapkan Unified Theory of Acceptance and Use Technology (UTAUT) buat mengPengujian penerimaan peserta didik terhadap aplikasi mobile learning pada perguruan tinggi. Data didapat menggunakan cara menyebarkan informasi lapangan secara online asal 697 mahasiswa. Metode SEM digunakan buat analisa data. yang akan terjadi menunjukaan bahwa kualitas isu, ketersediaan sumber daya, efektifitas diri, dan keamaan artinya variable primer untuk penerimaan aplikasi mobile learning ini. hasil dari penelitian ini memberikan info yg diharapkan perguruan tinggi buat dapat menaikkan penerimaan sistem pemebelajaran menggunakan mobile learning buat mendukung penggunaan teknologi seluler pada proses pembelajaran dan pengajaran (Almaiah, Alamri, \& AlRahmi, 2019).

\section{Kajian Literatur}

1. Sistem Informasi E-filing

Sistem Informasi $e$-filing merupakan suatu sistem yang dibangun untuk mengelola datadata laporan online pajak suatu lembaga pemerintah dengan penerapan teknologi komputer, sehingga proses kegiatan pelaporan bisa dikelola menjadi informasi yang berguna (Wahyuni, Putra, \& Wadisman, 2020).

2. Unified Theory of Acceptance and Use of Technology (UTAUT)

Model penerimaan (kerangka analisis) dibuat untuk membantu mendefinisikan dan memahami faktor-faktor yang mempengaruhi apakah suatu inovasi digunakan atau tidak. Unified Theory of Acceptance and Use ofTechnology (UTAUT) adalah model yang digunakan untuk menjelaskan perilaku pengguna terhadap penerimaan teknologi informasi (Andwika, Witjaksono, \& Azizah, 2020).

\section{Variable UTAUT}

Terdapat 4 variable pada model UTAUT yang dapat mempengaruhi niat perilaku untuk menggunakan atau mengadopsi sistem teknologi. Variable adalah sebagai berikut:

a. Performance Expectancy

Sejauh mana seseorang percaya bahwa penggunaan teknologi dapat meningkatkan kinerja mereka.

b. Effort Expectancy

Sejauh mana seseorang percaya bahwa teknologi dapat digunakan dengan mudah.

c. Social Influence

Sejauh mana seseorang percaya bahwa orang lain disekitar mereka percaya bahwa mereka harus menggunakan suatu teknologi tertentu.

\section{d. Facilitating Conditions}

Sejauh mana seseorang percaya bahwa dukungan fasilitas yang disediakan untuk memfasilitasi penggunaan teknologi (Rinjany, 2020).

4. Structure of the UTAUT Model

Struktur UTAUT model dapat dilihat seperti pada Gambar 1 (Isaias, Reis, Coutinho, $\&$ Lencastre, 2017).

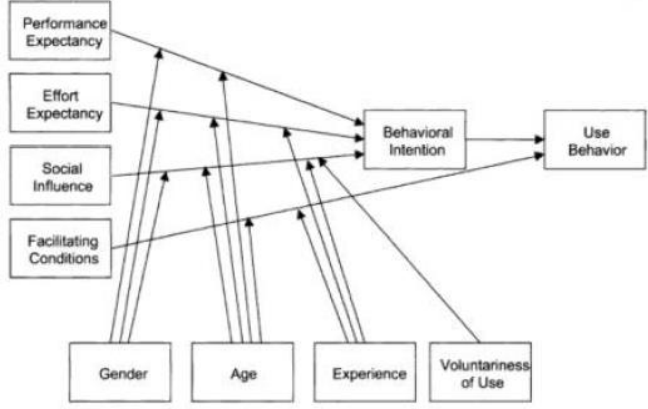

Gambar 1. Structure of the UTAUT Model

2. METODE PENELITIAN 
Kerangka kerja pada peneltian ini adalah proses tahapan untuk menyelesaikan permasalahan pada penelitian ini seprti pada Gambar 2.

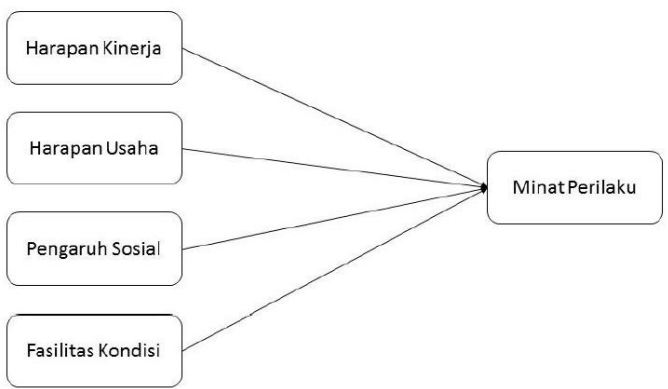

Gambar 2 . Kerangka Kerja Peneltian Berdasarkan kerangka kerja penelitian diatas, maka hipotesis penelitian ini dirumuskan sebagai berikut:

H1 : Apakah ekspektasi kinerja terkait dengan minat perilaku.

H2 : Apakah Ekspektasi usaha berhubungan dengan minat perilaku.

H3 : Apakah pengaruh sosial berhubungan dengan minat perilaku.

H4 : Apakah fasilitas kondisi berhubungan dengan minat perilaku.

\section{HASIL DAN PEMBAHASAN}

1. Karakteristik Variabel

Pada penelitian ini, empat variabel independen (akibat yg diperlukan, upaya yg diperlukan, imbas sosial, lingkungan yg mendukung) dan satu variabel dependen (niat sikap) dipergunakan. Responden diberikan 22 pertanyaan. pada penelitian ini, nilai statistik naratif buat variabel Pengujian menggunakan skala 1 sampai lima untuk setiap soal. Statistik deskriptif (minimum dan maksimum, mean, standar deviasi) buat seluruh pertanyaan yg digunakan pada informasi lapangan ditunjukkan di Tabel 1 di bawah ini :

Tabel 1. Karakteristik Variabel
Performance $\quad 1,00 \quad 5,00 \quad 3,47 \quad 3,41$

Expectancy

$\begin{array}{lllll}\text { Effort } & 1,00 & 5,00 & 3,32 & 4,10\end{array}$

Expectancy

Social $\quad 1,00 \quad 5,00 \quad 3,22 \quad 3,05$

Influence

Facilitating $\quad 1,00 \quad 5,00 \quad 3,33 \quad 4,03$

Condition

Behavioral $\quad 1,00 \quad 5,00 \quad 3,47 \quad 3,26$

intention

Tabel ini menunjukkan bahwa minat sikap rata-rata 3,47. adalah rata-rata responden putusan bulat bahwa minat perilaku berperan pada mempertinggi minat responden terhadap penggunaan sistem $e$ filing. Variabel ini menunjukkan standar deviasi 3,26 asal analisis di atas. Hal ini memberikan bahwa variabilitas yg dihasilkan berasal data variabel tadi sangat kecil.

rata-rata variabel hasil yg diperlukan ialah 3,47 yang berarti rata-rata responden putusan bulat bahwa yang akan terjadi yang diperlukan sudah diverifikasi, dan kesediaan responden buat memakai sistem e-filing meningkat. sesuai yang akan terjadi analisis di atas, variabel ini memiliki simpangan standar sebesar 3,41 yg berarti variasi dari data variabel tersebut cukup mungil.

Rata-rata variabel ekspektasi usaha adalah 3,32 yang berarti bahwa responden merasa sangat mudah menggunakan sistem e-filing, yang memperkuat keinginan mereka untuk menggunakan sistem e-filing. Hasil analisis untuk variabel ini memiliki simpangan baku sebesar 4,10 yang berarti variasi yang terjadi pada variabel ini cukup kecil.

Rata-rata variabel pengaruh sosial adalah 3,22, menunjukkan bahwa responden percaya bahwa mereka dapat memperoleh informasi yang cukup tentang sistem e-filing 
dari orang-orang di sekitar mereka. Hasil analisis untuk variabel ini memiliki standar deviasi sebesar 3,05 yang berarti variasi yang terjadi pada variabel ini sangat kecil.

Rata-rata variabel kapasitas bersyarat adalah 3,33, menunjukkan bahwa mahasiswa cukup puas dengan peluang sistem e-filing yang diberikan oleh Ditjen pajak atau lembaga, menunjukkan bahwa niat untuk menggunakan sistem e-filing meningkat. Hasil analisis untuk variabel ini memiliki standar deviasi 4,03 yang berarti variasi yang terjadi pada variabel ini cukup kecil.

\section{Hasil Pengujian Outlier}

Setelah dilakukan Pengujian terhadap 240 kuesioner yang telah diolah, ditemukan 8 data, dengan nilai lebih besar dari nilai $\mathrm{Z}$ yang ditentukan, yaitu -3 sampai 3 . Oleh karena itu, sampel datanya adalah 232 kuesioner. Hasil survei outlier ditunjukkan pada Tabel 2.

Tabel 2. Hasil Pengujian Outlier

\begin{tabular}{lcccc}
\hline & N & Min & Max & Kesimpulan \\
\hline ZscorePE & 232 & - & 2,13 & outlier \\
& & 3,15 & & \\
ZscoreEE & 232 & - & 1,97 & outlier \\
& & 3,30 & & \\
ZscoreSI & 232 & - & 1,98 & outlier \\
& & 3,68 & & \\
ZscoreFC & 232 & - & 1,78 & - \\
& & 2,98 & & \\
ZscoreBI & 232 & - & 1,88 & outlier \\
& & 3,47 & & \\
\hline
\end{tabular}

3. Hasil Pengujian Kualitas Data

Hasil Pengujian validasi untuk semua variabel menunjukkan bahwa setiap item pada variabel pertanyaan dinyatakan valid. Dalam penelitian ini, karena semua nilai setiap elemen variabel memiliki nilai lebih dan sama dengan 0,5 untuk setiap variabel, hal ini dapat dilihat seperti pada Tabel 3.

Tabel 3. Hasil Pengujian Validitas

\begin{tabular}{lcc}
\hline \multicolumn{1}{c}{ Variabel } & Loading Factor & Kesimpulan \\
\hline Performance Expectancy 1 (PE1) & 0,86 & valid \\
Performance Expectancy 2 (PE2) & 0,88 & valid \\
Performance Expectancy 3 (PE3) & 0,89 & valid \\
Performance Expectancy 4 (PE4) & 0,86 & valid \\
Effort Expectancy 1 (EE1) & 0,81 & valid \\
Effort Expectancy 2 (EE2) & 0,85 & valid \\
Effort Expectancy 3 (EE13 & 0,85 & valid \\
Effort Expectancy 4 (EE4) & 0,73 & valid \\
Effort Expectancy 5 (EE1) & 0,70 & valid \\
Social Influence 1 (SI1) & 0,74 & valid \\
Social Influence 2 (SI2) & 0,77 & valid \\
Social Influence 3 (SI3) & 0,80 & valid \\
Social Influence 4 (SI4) & 0,72 & valid
\end{tabular}


Facilitating Condition 1 (FC1)

Facilitating Condition 2 (FC2)

Facilitating Condition 3 (FC3)

Facilitating Condition 4 (FC4)

Facilitating Condition 5 (FC5)

Behavioral intention 1 (BI1)

Behavioral intention 2 (BI2)

Behavioral intention 3 (BI3)

Reliabilitas adalah sebuah cara untuk mengetahui apakah setiap butir item pada variabel itu dijawab secara konsisten. Untuk hasil dari penelitian silahkan lihat Tabel 4 .

Tabel 4. Hasil Pengujian Reliabilitas

\begin{tabular}{ccc}
\hline Variabel & $\begin{array}{c}\text { Cronbach's } \\
\text { Alpha }\end{array}$ & Kesimpulan \\
\hline $\begin{array}{c}\text { Performance } \\
\text { expectancy }\end{array}$ & 0,80 & Reliabel \\
$\quad \begin{array}{l}\text { Effort } \\
\text { Expectancy }\end{array}$ & 0,77 & Reliabel \\
$\quad \begin{array}{l}\text { Social } \\
\text { Influence }\end{array}$ & 0,79 & Reliabel \\
$\begin{array}{c}\text { Facilitating } \\
\text { Condition }\end{array}$ & 0,77 & Reliabel \\
$\begin{array}{c}\text { Behavioral } \\
\text { intention }\end{array}$ & 0,76 & Reliabel
\end{tabular}

Hasil Pengujian menunjukkan bahwa variabel seperti kinerja yang diharapkan, waktu usaha yang diharapkan, dampak sosial, kemungkinan lingkungan, dan niat perilaku dinyatakan dapat diandalkan. Hal ini dikarenakan nilai yang diperoleh dari data survey adalah lebih dan sama dengan 0,6 .

\section{Hasil Pengujian Asumsi Klasik}

Pengujian hipotesis klasik meliputi Pengujian normalitas, Pengujian multikolinearitas, dan Pengujian varians. Hasil Pengujian masing-masing Pengujian

$\begin{array}{ll}0,70 & \text { valid } \\ 0,78 & \text { valid } \\ 0,88 & \text { valid } \\ 0,84 & \text { valid } \\ 0,68 & \text { valid } \\ 0,82 & \text { valid } \\ 0,86 & \text { valid } \\ 0,90 & \text { valid }\end{array}$

hipotesis klasik disajikan dalam uraian berikut:

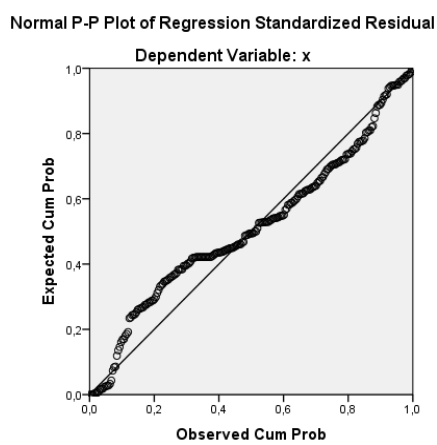

Gambar 3

Hasil Pengujian Normalitas P-P Plot Gambar 3 diatas dapat dilihat bahwa plot variabel behavioral intention berdasarkan grafik P-Plot, terlihat bahwa data menyebar dari bawah ke atas disekitar garis diagonal dan mengikuti garis diagonalnya. Hal ini menunjukkan bahwa pola distribusinya mendekati normal.

\section{Hasil Uji Multikolinearilitas}

Pengujian multikolinearitas berfungsi sebagai apakah terdapat korelasi diantara variable bebas pada model regresi. Korelasi pada varaible independent seharusnya tidak terjadi pada model regresi. Untuk menguji multikolenearitas dapat menggunakan besaran nilai variance inflation factor (VIF) dan tolerance. Hasil pengujian dapat dilihat seperti pada Tabel 5 .

Tabel 5. Hasil Uji Multikolinieritas 


\begin{tabular}{|c|c|c|c|}
\hline Variabel & Tolerance & VIF & Kesimpulan \\
\hline $\begin{array}{l}\text { Performance } \\
\text { Expectancy }\end{array}$ & 0,74 & 1,34 & $\begin{array}{c}\text { Tidak terjadi } \\
\text { multikolinearitas }\end{array}$ \\
\hline $\begin{array}{l}\text { Effort } \\
\text { Expectancy }\end{array}$ & 0,63 & 1,56 & $\begin{array}{c}\text { Tidak terjadi } \\
\text { multikolinearitas }\end{array}$ \\
\hline $\begin{array}{l}\text { Social } \\
\text { Influence }\end{array}$ & 0,58 & 1,69 & $\begin{array}{c}\text { Tidak terjadi } \\
\text { multikolinearitas }\end{array}$ \\
\hline $\begin{array}{l}\text { Facilitating } \\
\text { Condition }\end{array}$ & 0,58 & 1,72 & $\begin{array}{c}\text { Tidak terjadi } \\
\text { multikolinearitas }\end{array}$ \\
\hline
\end{tabular}

Hasil pengujian pada Tabel 5 dapat dilihat keempat variable independent memiliki nilai VIF $<10$ dan Tolerance $>$ 0,10 dimana masih dalam batas toleransi sehingga tidak terjadi multikolinearitas pada variable ini.

\section{Hasil Uji Heteroskedastisitas}

Hasil pengujian heteroskedastisitas dapat dilihat seperti pada Gambar 4. Pada gambar 4 bisa dilihat bahwa titik tidak membentuk suatu pola, melainkan acak sehingga dari hasi pengujian tidak terjadi heteroskedatisitas karena pengujian ini merupakan pengujian yang digunakan untuk melihat variable bisa dianggap mengganggu apabila mempunya variable yang sama atau tidak. Pengujian pada heteroskedistisitas menggunakan uji grafik pada scatter plot dimana variable dependent terletak pada sumbu $\mathrm{x}$ dan residial pada masing-masing idependent di bagian sumbu y. Apabila pada grafik penyebaran data terlihat acak dan tidak terjadi pembentukan pola khusus, maka tidak terjadi gejala heterokedastisitas.

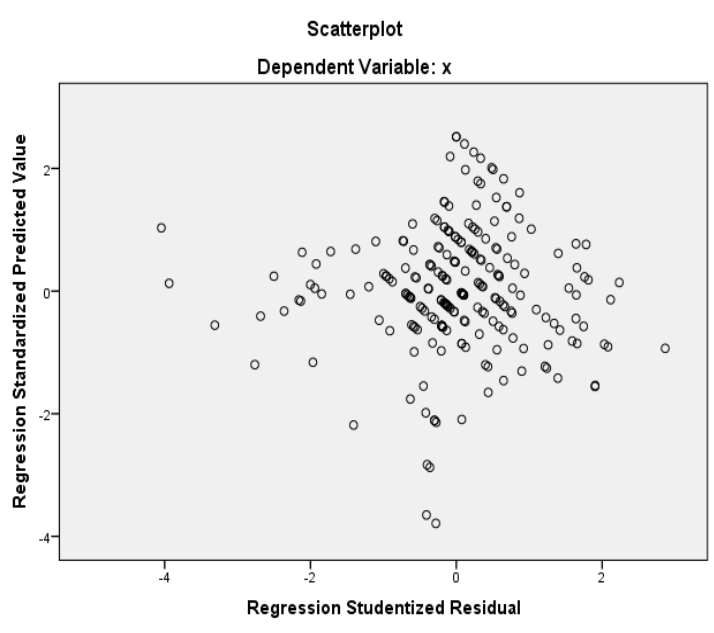

Gambar 4. Hasil Uji Heteroskedastisitas

\section{Hasil Uji Hipotesis}

Pengujian hasil hipotesis yaitu menggunakan analisisis regresi berganda(multiple regression). Dari hasil pengujian dapat dilihat hasil dari uji $\mathrm{F}$, t, dan determinasi seperti pada Table6.

Tabel 6. Hasil Uji F

\begin{tabular}{cccc}
\hline Variabel & F & Sig. & Kesimpulan \\
\hline $\begin{array}{c}\text { Behavioral } \\
\text { intention }\end{array}$ & 50,40 & $0,00^{\mathrm{b}}$ & Signifikan \\
\hline
\end{tabular}

Hasil pengujian $\mathrm{F}$ nilai yang diperoleh sebesar 50,40 dengan nilai probabilitas sebesar 0.000. jika nilai probabilitas $0.000<$ 0.005, maka variable performance expectancy, effort expectancy, social influence \& facilitating condition berpengaruh terhadap variable behavioral intention. Pengujian $t$ berguna untuk meilhat tingkat signifikasi pada varible independent terhadap variable dependent. Pengujian nilai sisnifikansi dapat dilihat seperti pada Table7. Hasil dari pengujian nilai signifikansi pada $\mathrm{t}$ dari variable performance expectancy, effort expectancy, social influence, facilitating condition terhadap 
minat perilaku pengguna sistem informasi akademik Universitas Internasional Batam.
Tabel 8. Hasil Uji Koefisien Korelasi (R) dan Koefisien Determinasi (Adjusted $\mathrm{R}^{2}$ )

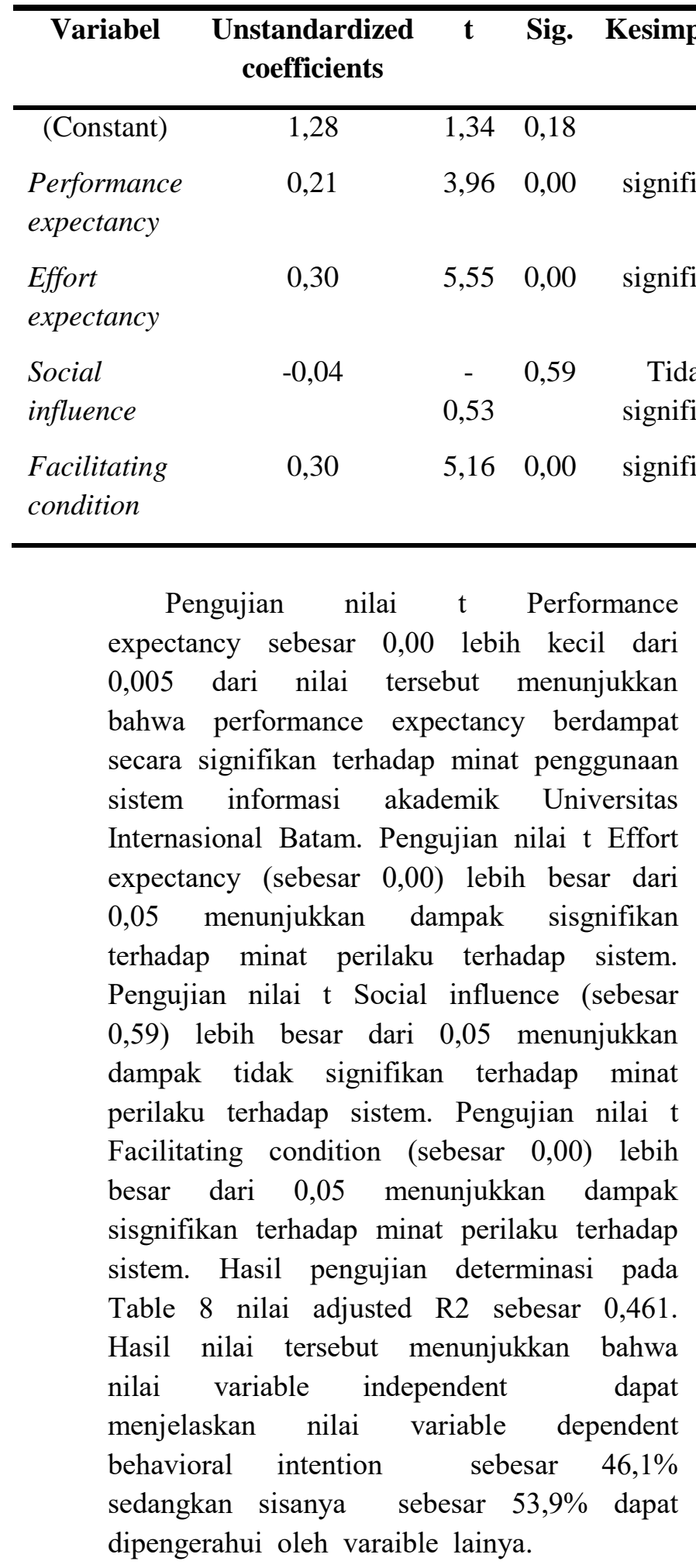

\section{Variabel}

$\mathbf{R}$

Adjusted R Square \begin{tabular}{l} 
Behavioral $0,686^{\mathrm{a}}$ \\
intention \\
\hline 4. KESIMPULAN \\
Berdasarkan hasil analisis menggunakan \\
metode Theory Of Acceptance and Use Of \\
Technology (UTAUT) menggunakan empat \\
variable pengujian yaitu harapan kinerja,
\end{tabular} \begin{tabular}{l} 
Behavioral $0,686^{\mathrm{a}}$ \\
intention \\
\hline 4. KESIMPULAN \\
Berdasarkan hasil analisis menggunakan \\
metode Theory Of Acceptance and Use Of \\
Technology (UTAUT) menggunakan empat \\
variable pengujian yaitu harapan kinerja,
\end{tabular} \begin{tabular}{l} 
Behavioral $0,686^{\mathrm{a}}$ \\
intention \\
\hline 4. KESIMPULAN \\
Berdasarkan hasil analisis menggunakan \\
metode Theory Of Acceptance and Use Of \\
Technology (UTAUT) menggunakan empat \\
variable pengujian yaitu harapan kinerja,
\end{tabular} \begin{tabular}{l} 
Behavioral $0,686^{\mathrm{a}}$ \\
intention \\
\hline 4. KESIMPULAN \\
Berdasarkan hasil analisis menggunakan \\
metode Theory Of Acceptance and Use Of \\
Technology (UTAUT) menggunakan empat \\
variable pengujian yaitu harapan kinerja,
\end{tabular} harapan usaha, pengaruh sosial, dan kondisi fasilitas. Variable pengaruh sosial hasilnya tidak sesuai harapan para responden karena kurangnya sosialisasi terhadap sistem e-filing pada ditjen pajak. Sedangkan variable harapan kinerja, harapan usaha, dan kondisi fasilitas mendapatkan hasil responden yang baik dan puas dengan layanan sistem $e$ filing ditjen pajak

\section{DAFTAR PUSTAKA}

Almaiah, M. A., Alamri, M. M., \& Al-Rahmi, W. (2019). Applying the UTAUT Model to Explain the Students' Acceptance of Mobile Learning System in Higher Education. IEEE Access, 7, 174673174686.

https://doi.org/10.1109/ACCESS.2019.29 57206

Andwika, V. R., Witjaksono, R. W., \& Azizah, A. H. (2020). Analysis of User Acceptance of ERP System on After Sales Function Using Unified Theory of Acceptance and Use of Technology (UTAUT) Model. International Journal of Advances in Data and Information Systems, $\quad 1(1), \quad 26-33$. https://doi.org/10.25008/ijadis.v1i1.178

Anggraini, S., Irfani, M. H., \& Rahayu, S. (2020). Analisis Penerimaan Sistem Informasi Akademik Dengan 
Menggunakan UTAUT 2 (Studi Kasus: Akademi Keperawatan Pembina Palembang). Jusifo, 6(1), 15-30. https://doi.org/10.19109/jusifo.v6i1.5616

Aprilisa, S., Samsuryadi, S., \& Sukemi, S. (2021). Pengujian Validitas dan Reliabilitas Model UTAUT 2 dan EUCS Pada Sistem Informasi Akademik. Jurnal Media Informatika Budidarma, 5(3), 1124-1132.

https://doi.org/10.30865/mib.v5i3.3074

Isaias, P., Reis, F., Coutinho, C., \& Lencastre, J. A. (2017). EMPATHIC TECHNOLOGIES FOR DISTANCE AND MOBILE LEARNING: AN EMPIRICAL RESEARCH BASED ON UNIFIED THEORY OF ACCEPTANCE AND USE OF TECHNOLOGY (UTAUT). Interactive Technology and Smart Education, 14(2). https://doi.org/10.1108/ITSE-02-20170014

Jahanshahi, D., Tabibi, Z., \& van Wee, B. (2020). Factors influencing the acceptance and use of a bicycle sharing system: Applying an extended Unified Theory of Acceptance and Use of Technology (UTAUT). Case Studies on Transport Policy, 8(4), 1212-1223. https://doi.org/10.1016/j.cstp.2020.08.002

Masril, M. A., \& Noviardi, R. (2020). Analisa Morfologi Dilasi untuk Perbaikan Kualitas Citra Deteksi Tepi pada Pola Batik Menggunakan Operator Prewitt dan Laplacian of Gaussian. Jurnal RESTI (Rekayasa Sistem Dan Teknologi Informasi), 4(6), 1052-1057. https://doi.org/10.29207/resti.v4i6.2601

Rinjany, D. K. (2020). Does Technology Readiness and Acceptance Induce more Adoption of E-Government? Applying the UTAUT and TRI on an Indonesian Complaint-Based Application. Policy \& Governance Review, 4(3), 68-86. https://doi.org/10.30589/pgr.v4i1.157

Šumak, B., \& Šorgo, A. (2016). The acceptance and use of interactive whiteboards among teachers: Differences in UTAUT determinants between pre- and postadopters. Computers in Human Behavior, 64 , 602-620.
Wahyuni, S., Putra, R. R., \& Wadisman, C. (2020). Pengembangan Sistem Informasi Akademik Berbasis Web Sma/Smk Yapim Taruna Marelan. Journal of Information Technology and Computer Science (INTECOMS), 3(1), 52-59. https://doi.org/10.1016/j.chb.2016.07.037 